\title{
FORMAÇÃO PROFISSIONAL DO ASSISTENTE SOCIAL NA CONTEMPORANEIDADE: ASPECTOS DA INTERDISCIPLINARIDADE
}

\author{
Cirlene Aparecida Hilário Silva de Oliveira ${ }^{1}$ \\ Tatiana Machiavelli Carmo Souza ${ }^{2}$
}

\begin{abstract}
Resumo
O presente artigo se propõe a compreender a importância da interdisciplinaridade na formação profissional do assistente social. Frente às transformações do mundo globalizado, espera-se que o assistente social encontre respostas sólidas diante das especificidades da questão social. Nesse sentido, a proposta do trabalho interdisciplinar se apresenta como uma possibilidade de compartilhamento de conhecimentos e saberes que auxiliam na compreensão das relações sociais e que permita a superação de idéias já concebidas. Para que a prática interdisciplinar se efetive faz-se necessário repensar a formação profissional no Serviço Social, uma vez que é neste momento que o futuro profissional poderá desenvolver habilidades que a contemporaneidade exige.
\end{abstract}

Palavras-chave: formação profissional, interdisciplinaridade, serviço social, assistente social.

Na história da sociedade, os agentes são homens
dotados de consciência, que agem movidos pela
reflexão ou a paixão, perseguindo determinados
objetivos; nada acontece aí sem uma intenção
consciente, sem um objetivo colimado.
Marx - Engels

Ao pensarmos a formação profissional do Assistente Social precisamos apreender o cenário em que a profissão se efetiva, bem como a realidade social que a cerca. Acredita-se que as mudanças políticas, sociais, culturais e ideológicas, que vivemos nos tempos atuais; as profundas transformações nos processos de produção e reprodução da vida social; assim como as relações entre os sujeitos, nos impulsionam a refletir sobre as novas demandas e dinâmicas do mundo do trabalho.

Esta nova conjuntura da realidade reafirma a necessidade de superação de práticas, nos impulsionando a ter um olhar instigante para o mundo contemporâneo. Mais do que compreender o significado e papel da profissão na sociedade do capital diante do processo de reprodução das relações sociais, as novas necessidades do mercado de trabalho demanda uma formação profissional que propicie aos Assistentes Sociais subsídios teóricos, éticos, políticos e técnicos

\footnotetext{
${ }^{1}$ Docente da Graduação e do Programa de Pós-Graduação em Serviço Social da UNESP/Franca, Líder do Grupo de Estudos e Pesquisa Formação Profissional em Serviço Social, Supervisora da Unidade Auxiliar Centro Jurídico Social/UNESP, cirlene.olveira@uol.com.br

${ }^{2}$ Psicóloga na Prefeitura Municipal de Itirapuã, Aluna Especial do Programa de Pós-Graduação em Serviço Social da UNESP/Franca, Membro do Grupo de Estudos e Pesquisa Formação Profissional em Serviço Social, tatimachiavelli@yahoo.com.br
} 
que auxiliem no desenvolvimento de habilidades que possibilitarão uma ação crítica, criativa e comprometida.

\begin{abstract}
A contemporaneidade exige cada vez mais profissionais qualificados, dotados de conhecimentos especializados e atualizados, flexibilidade intelectual no encaminhamento de diferentes situações e capacidade de análise para decodificar a realidade social (Oliveira, 2003, p 43).
\end{abstract}

Nesse contexto, acredita-se que a formação profissional, na atualidade, deve ser (re)pensada, a fim de que possamos possibilitar a capacitação de profissionais condizentes com novas dinâmicas de trabalho.

Quando falamos em formação profissional estamos pensando num processo dialético, portanto, aberto e dinâmico, que traz a possibilidade de aprendizagem e compreensão da realidade que nos cerca. Caracterizado por ser um processo vivo, a formação profissional encontra-se sempre em movimento, orientando-se para o crescimento e fortalecimento do Serviço Social. Nesse sentido, Gonçalves e Higuchi (1998) apontam a formação profissional como um processo, como uma práxis (ação-reflexão-ação) que leva ao desenvolvimento de habilidades necessárias ao desempenho profissional.

Batista in Fazenda (2002) propõe que a formação atravessa e constitui a história dos homens como seres sociais e por isso traz consigo dimensões subjetivas e dimensões intersubjetivas. Formar é possibilitar um processo de abertura a partir do qual algo possa vir-aser.

A formação profissional da qual estamos tratando deve buscar eficiência e modernização, capacitando o profissional para uma atuação de nível macro.

Parte-se do pressuposto de que a formação profissional, numa realidade específica, não pode ser considerada isoladamente da realidade social, expressa pelo aspecto estrutural e conjuntural, pelo sistema educativo em geral, e, especificamente, pelo e ensino superior, como contexto da formação profissional, a qual, necessariamente, reflete o movimento histórico da própria sociedade (Silva, 1984, p 5).

Nesse sentindo, pensar a formação profissional é refletir sobre o desenvolvimento do Serviço Social na sociedade brasileira. Faz-se necessário o desenvolvimento de uma proposta de formação profissional conciliada com a atualidade, comprometida com os valores democráticos, com um novo ordenamento das relações sociais.

Tanto em sua natureza, quanto no seu conteúdo, a formação do Assistente Social diferencia-se por suas particularidades institucionais, mas também se caracteriza pela diversidade de paradigmas interligados a outras ciências. É nesse sentido que integrar o heterogêneo se 
apresenta como um desafio na contemporaneidade, desafio que requer vontade, disposição e a superação de caminhos já existentes.

Diante da globalização, das divisões no campo social, cultural, financeiro, político, científico, etc., em particular da fragmentação na maneira de perceber e compreender o ser humano e suas relações, a interdisciplinaridade emerge como prática de articulação destas partes. Podemos afirmar que, mais que uma proposta simplista, a interdisciplinaridade pode apresentarse como uma resposta de intercâmbio e integração, uma maneira de transpor fronteiras e diferenças existentes entre as profissões, a fim de alcançar uma comunicação mais efetiva.

Compreendemos o ser humano como produto e produtor da história, isto é, partindo de um olhar materialista-histórico e dialético, busca-se estudar o processo no qual a realidade objetiva vivida pelo indivíduo se torna subjetiva. Como apontam Lane \& Sawaia (1995) o ser humano só o é na relação com os outros. É a partir dessas relações sociais que estaremos nos propondo a discutir a interdisciplinaridade.

Oliveira (2003) aponta a interlocução entre os variados pólos do saber como uma característica inevitável do mundo organizado do conhecimento. A interdisciplinaridade transcende a união de forças para a obtenção de um objetivo comum, ela possibilita o diálogo, a troca de conceitos e idéias, a criatividade.

Fazenda (2002) nos aponta que a interdisciplinaridade é uma atitude coletiva diante da questão do conhecimento, um projeto em que causa e intenção coincidam, um fazer que surja de um ato de vontade e que, portanto, exige uma imersão no trabalho cotidiano. Dessa forma, a interdisciplinaridade caracteriza-se pela intensidade das trocas entre especialistas e pela integração das disciplinas num mesmo projeto.

A interdisciplinaridade tem como princípio constituinte a diferença. Sabe-se que é próprio do ser humano a dificuldade em conviver com as diferenças, com o diferente. Percebemos, assim, que efetivar a interdisciplinaridade requer uma nova postura profissional, como apresenta Martinelli (1995), "um novo saber ético e social". Faz-se necessário rever as próprias práticas e caminhar rumo a um amadurecimento profissional.

Acredita-se que a base do trabalho interdisciplinar seja a interdependência entre os profissionais envolvidos, reconhecendo a área particular de competência de cada um, mas aliado à mútua compreensão e respeito, busque-se a superação do conhecimento já existente da realidade social.

A perspectiva interdisciplinar não fere a especificidade das profissões e tampouco seus campos de especialidade. Muito pelo contrário, requer a originalidade e a diversidade dos conhecimentos que produzem e sistematizam acerca de determinado objeto, de determinada prática, permitindo a pluralidade de contribuições para compreensões mais consistentes deste mesmo 
objeto, desta mesma prática (Martinelli, 1995, p 157).

Pombo (2006) vai de encontro com esta idéia ao apresentar a interdisciplinaridade como um processo de fecundação recíproca das disciplinas no qual cada disciplina envolvida se deixa cruzar e contaminar pelas outras.

A interdisciplinaridade traz como conseqüência a modificação de conceitos, terminologias e posicionamentos, superando as endogenias e efetivando a pluralidade de saberes. Desta forma, o trabalho interdisciplinar desencadeia um crescimento profissional, bem como um crescimento institucional, porque exerce uma prática solidária (Oliveira, 2003).

Para Erich Jantsch:

A interdisciplinaridade propriamente dita é algo diferente, que reúne estudos complementares de diversos especialistas em um contexto de estudo de âmbito mais coletivo. A interdisciplinaridade implica numa vontade e compromisso de elaborar um contexto mais geral, na qual, cada uma das disciplinas em contato são por sua vez modificadas e passam a depender claramente umas das outras. Aqui se estabelece uma interação entre duas ou mais disciplinas, o que resultará em intercomunicação e enriquecimento recíproco e, consequentemente, em uma transformação de suas metodologias de pesquisa, em uma modificação de conceitos, de terminologias fundamentais etc. Entre as diferentes matérias ocorrem intercâmbios mútuos e recíprocas interações; existe um equilíbrio de forças nas relações estabelecidas (apud Santomé, 1996, p 73).

Como forma de trabalho criativo e totalizante, a interdisciplinaridade reconhece de forma dialética a necessidade de olhares diferenciados para um mesmo objeto. Dessa forma, desenvolver um trabalho interdisciplinar é uma atitude individual que esbarra na intersubjetividade (relação entre sujeitos).

A transformação das práticas deve perpassar a mudança interior, que nos conduz a uma mudança de atitude. O caminho é o do diálogo, das trocas, dos encontros e, principalmente, pela verdade. Isso requer uma atitude de desacomodar-se, um movimento que nos tire da zona de conforto, que nos impulsione a buscar o novo.

A interdisciplinaridade pode ser entendida como um instrumento, um modo de superar o isolacionismo das disciplinas, um empreendimento que objetiva atender objetivos sociais e políticos (Japiassu, 1976).

Por intervir no campo social, o Serviço Social não pode se caracterizar como uma prática solitária, uma vez que diversas áreas incidem sobre este campo. Entretanto, sabe-se que é próprio 
do ser humano as dificuldades em conviver com as diferenças, por isso, também, que ir além de si mesmo e reconhecer no outro uma possibilidade de superação mostra-se tarefa tão árdua.

O trabalho interdisciplinar não acontece imediatamente, ele se efetiva na sua prática e vivência. Sua complexidade incide em avanços e retrocessos diretamente relacionados aos profissionais que compõem a equipe. Nesse sentido, o avanço do trabalho ocorrerá a partir do levantamento dos entraves que emergem no cotidiano do trabalho, no compartilhamento de conhecimentos e saberes.

Enfim, não estamos aqui para apresentar o interdisciplinar como o remédio para a cura de todos os males, pois isso seria uma atitude insana. Mas para nós, a interdisciplinaridade mostra-se como uma maneira de intervir no mundo, efetivada pela transformação dos espaços, das relações, pelo construir. Mesmo sendo um processo difícil de atingir, ainda que a interdisciplinaridade não exista como algo definitivo, acreditamos que seja um caminho possível de ser alcançado através do reconhecimento da importância de cada área do saber e do respeito mútuo entre os profissionais.

Acreditamos que em sua formação profissional o Assistente Social tem um espaço fecundo para compreender o trabalho interdisciplinar e efetivá-lo. Realizar um projeto interdisciplinar não requer um conjunto de procedimentos ou receitas, mas como nos mostra Japiassu (1976) a interdisciplinaridade revela o diálogo fecundo, onde as pessoas envolvidas são capazes de reconhecer aquilo que lhes falta e ofertar o seu conhecimento.

\section{REFERÊNCIAS BIBLIOGRAFICAS}

FAZENDA, I. C. A. (org.) (2002). Dicionário em construção: interdisciplinaridade. São Paulo: Cortes.

GONÇALVES, C. A.; HIGUCHI, P. (1998). Interdisciplinaridade: discurso ou realidade? Um estudo do cotidiano no Centro Jurídico Social. Franca: UNESP/FHDSS.

IRIBARRY, I. N. (2003). Aproximações sobre a transdisciplinaridade: algumas linhas históricas, fundamentos e princípios aplicados ao trabalho de equipe. Psicologia: Reflexão e Crítica, 16(3).

JAPIASSU, H. (1976). Interdisciplinaridade e patologia do saber. Rio de Janeiro: Imago.

LANE, S. T. M.; SAWAIA, B. B. (orgs.) (1995). Novas veredas da psicologia social. São Paulo: Brasiliense, EDUC.

MARTINELLI, M. L. (1989). Serviço social: identidade e alienação. São Paulo: Cortez. 
MARTINELLI, M. L. (coord.) (1994). O uso de abordagens qualitativas na pesquisa em serviço Social: um instigante desafio. PUC.

MARTINELLI, M. L.; RODRIGUES, M. L.; MUCHAIL, S. T. (1995). O uno e o múltiplo nas relações entre as áreas do saber. São Paulo: Cortez.

OLIVEIRA, C. A. H. S. (2003). A centralidade do estágio supervisionado na formação profissional em Serviço Social. Franca: UNESP/FHDSS.

POMBO, O. (2006, JAN/JUN). Práticas interdisciplinares. Sociologias. 1(15).

SANTOMÉ, J. T. (1996). Globalização e interdisciplinaridade: o currículo integrado. Porto Alegre: Artes Médicas.

SILVA, M. O. S. (1984). Formação profissional do assistente social: inserção na realidade social e na dinâmica da profissão. São Paulo: Cortez. 